\title{
Toxicity Prediction of meso-5,15-di[3,4-bis(carboxymethylenoxy)phenyl] porphyrin and meso-5,15-di[3,4-bis(carboxymethylenoxy)phenyl],10,20- diphenyl porphyrin
}

\author{
Fauzan Zein Muttaqin ${ }^{1,2 *}$, Slamet Ibrahim ${ }^{1}$, Abdul Muthalib ${ }^{3}$, Daryono H. Tjahjono ${ }^{1}$ \\ ${ }^{1}$ School of Pharmacy, Bandung Institute of Technology, Jalan Ganesha 10, Bandung 40132, Indonesia. \\ ${ }^{2}$ Bandung School of Pharmacy, Jalan Soekarno Hatta No 754 Cibiru, Bandung Indonesia. \\ ${ }^{3}$ Center of Radionuclides and Radiopharmaceuticals, National Atomic Agency, Serpong, Indonesia.
}

Received: 15 Oktober, 2014 / Accepted: 30 November 2014

\begin{abstract}
:
Porphyrin and its derivatives are widely investigated for cancer therapy because of their high selectivity to cancer cells. By labeling gamma and beta emitting-radionuclides to a porphyrin which selectively binds to the cancer tissue will produce a safe and potential radiopharmaceutical. The present study aims to predict the toxicity of meso-5,15-di[3,4-bis(carboxymethylenoxy)phenyl]-porphyrin $\left(\mathrm{D}_{3,4} \mathrm{BCPP}\right)$ andmeso-5,15-di[3,4-bis(carboxymethylenoxy)phenyl],10,20-diphenylporphyrin $\left(\mathrm{D}_{3,4} \mathrm{BCPDPP}\right)$ as well as their complexes with Rhenium (Re).Toxicity prediction using ADMET Predictor ${ }^{\mathrm{TM}}$ showed that $\mathrm{D} 3,4 \mathrm{BCPP}$ has an acute toxicity in rat; $\mathrm{D}_{3,4} \mathrm{BCPDPP}$ has an acute toxicity in rat and hepatotoxic; $\mathrm{Re}-\mathrm{D}_{3,4} \mathrm{BCPP}$ has an acute toxicity in rat, hepatotoxic, and likely carcinogenic in rat in which requiring microsomal activation mechanism; and Re-D3,4BCPDPP has an acute toxicity in rat and hepatotoxic.
\end{abstract}

Key words: ADMET, radionuclides,porphyrin, Toxicity Prediction

\section{Introduction}

Cancer is one of diseases that causes the highest mortality in the world. Late detection of cancer will increase the risk of mortality to the patients. Actually, low level stadium cancer can be overcome with several kinds of cancer therapy. Thus, early detection and therapy will lower the risk of mortality to the patients. All this time, the cancer treatment is carried out using radiation, chemotherapy, combination of radiation and chemotherapy, and surgery. Cancer treatment using radiation is still unable to give satisfactory results, whereas chemotherapy is not selective and often induces a second primary cancer as a result of the carcinogenic properties generally owned by the compounds. Similarly, removal of the cancer tissue by surgery is still incomplete. Therefore, it is necessary to find more effective and safe techniques for cancer diagnosis and therapy [1,2].

Cancer diagnosis and therapy using radiopharmaceuticals is one of the best alternatives to overcome this problem. By labeling gamma and beta emitting-radionuclides to a carrier compounds which selectively bind to the cancer tissue will produce a safe and potential radiopharmaceutical. The gamma radiation of radionuclide can be used for diagnosis, while the amount of energy from the beta particles can be used to kill cancer cells. The role of the carrier compound to deliver the gamma and beta radiation to the cancer cells will lead the appropriate selective and safe diagnosis and treatment [3].

Porphyrin and its derivatives are widely investigated for cancer therapy because of their high selectivity to cancer cells. This study aims to predict the toxicity of meso5,15-di-[3,4-bis (carboxymethylenoxy) phenyl] porphyrin and meso-5,15-di-[3,4-bis (carboxymethylenoxy) phenyl],10,20-diphenyl porphyrin and their complexes with rhenium.

In the present study, toxicity prediction of porphyrins and its complexes was carried out using ADMET Predictor $^{\mathrm{TM}}$ to predict their safety for future application as radiopharmaceuticals.

\section{Experimental}

The toxicity prediction was carried out using Central Processing Unit of Intel ${ }^{\circledR}$ i5 Processor, DDR3 8GB RAM, ATI Radeon 128 bit DDR3 1GB VGA Card, and Gauss View 03, Gaussian 03 Revission-B.04, and ADMET Predictor ${ }^{\mathrm{TM}}$ softwares. Molecular modeling using Gauss View 03 and Gaussian 03 Revission-B.04 was carried out to draw and optimize the structure of meso-5,15-di-[3,4-bis (carboxy-methylenoxy) phenyl] porphyrin (D3,4BCPP) and meso-5,15-di[3,4-bis (carboxymethylenoxy) phenyl], 10,20-diphenyl porphyrin $\left(\mathrm{D}_{3,4} \mathrm{BCPDPP}\right)$, their complexes to rhenium, and their derivatives. 


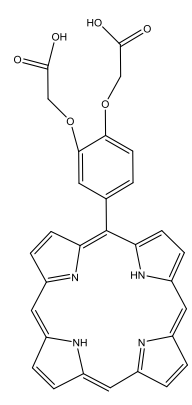

$\mathrm{M}_{3,4} \mathrm{BCPP}$

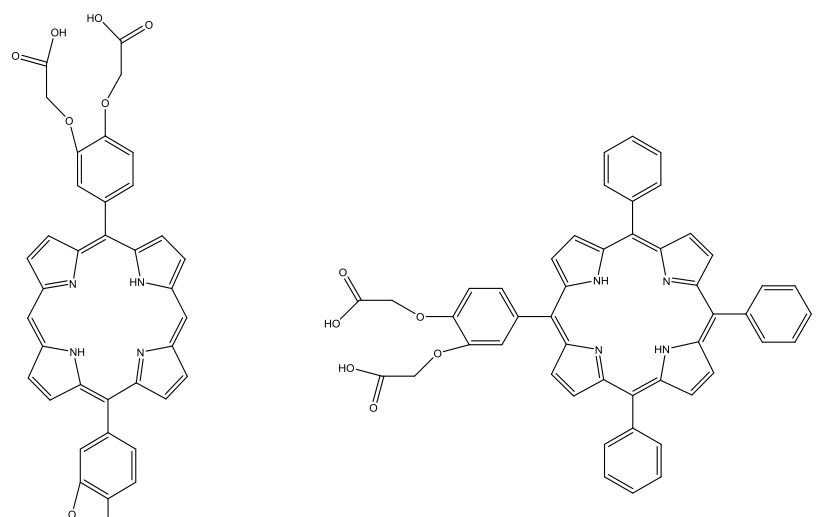

$\mathbf{M}_{3,4} \mathrm{BCPTPP}$

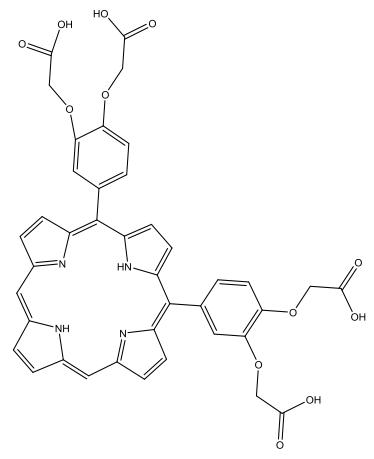

$\mathrm{CD}_{3,4} \mathrm{BCPP}$

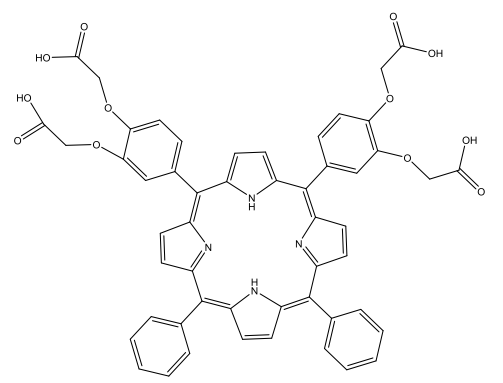

$\mathbf{c D}_{3,4}$ BCPDPP

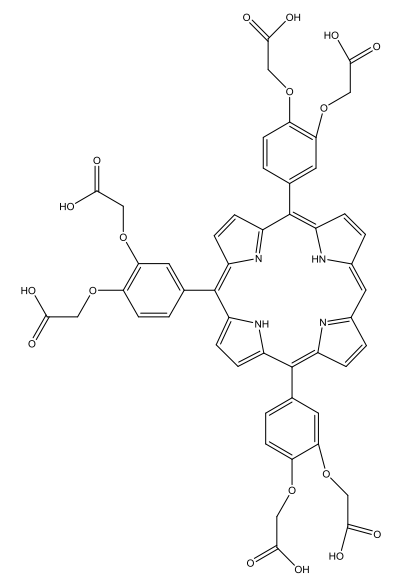

$\operatorname{Tr}_{3,4} \mathbf{B C P P}$

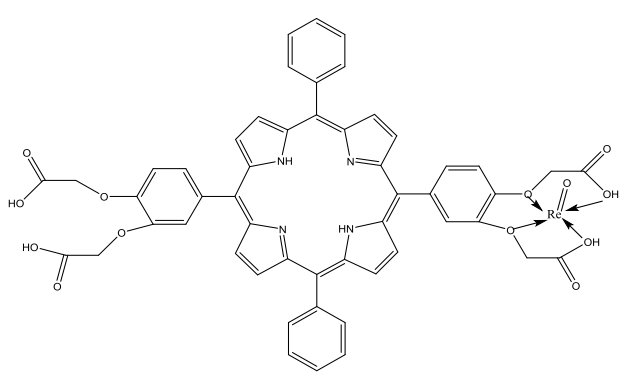

$\operatorname{Re}-D_{3,4} B C P D P P$

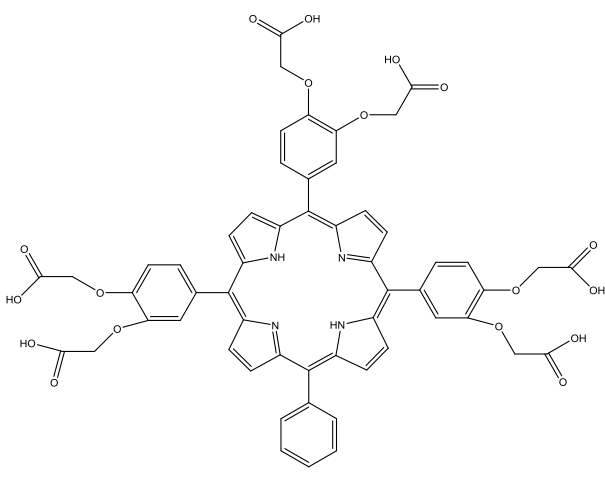

$\operatorname{Tr}_{3,4} \mathbf{B C P P P}$

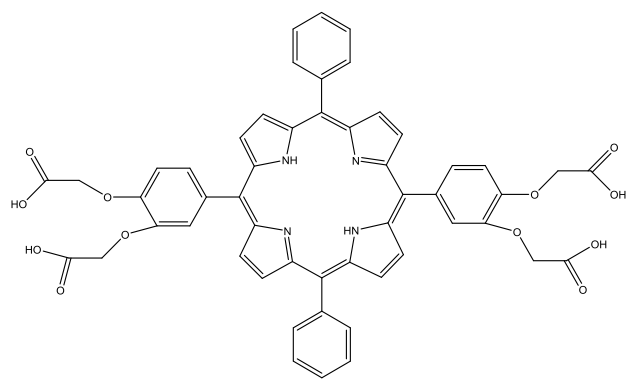

$\mathrm{D}_{3,4} \mathrm{BCPDPP}$

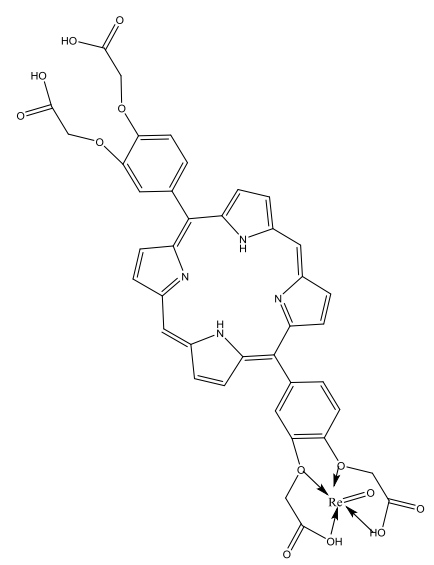

$\operatorname{Re}-D_{3,4} B C P P$

Figure 1. Chemical structure of $\mathrm{D}_{3,4} \mathrm{BCPP}, \mathrm{D}_{3,4} \mathrm{BCPDPP}$, and their derivatives.

$\mathbf{M}_{3,4} \mathbf{B C P P}$

$D_{3,4}$ BCPP

Re- $D_{3,4} B C P P$

$\mathbf{C D}_{3,4} \mathrm{BCPP}$

$\operatorname{Tr}_{3,4}$ BCPP

$M_{3,4}$ BCPTPP

$D_{3,4}$ BCPDPP

Re- $D_{3,4}$ BCPDPP

$\mathrm{CD}_{3,4} \mathrm{BCPDPP}$

$\mathrm{Tr}_{3,4} \mathrm{BCPPP}$
$=$ meso $-5-$ mono $[3,4-$ bis (carboxymethylenoxy) phenyl $]$ porphyrin

$=$ meso $-5,15-$ di $[3,4-$ bis (carboxymethylenoxy) phenyl $]$ porphyrin

$=$ Re-meso $-5,15$-di [3,4- bis (carboxymethylenoxy) phenyl] porphyrin

$=$ meso $-5,10$-cis $-\mathrm{di}[3,4$ - bis (carboxymethylenoxy) phenyl] porphyrin

$=$ meso $-5,10,15-\operatorname{tri}[3,4-$ bis (carboxymethylenoxy) phenyl $]$ porphyrin

$=$ meso-5 - mono [3,4-bis(carboxymethylenoxy)phenyl],10,15,20-triphenyl porphyrin

$=$ meso- 5,15- di [3,4- bis (carboxymethylenoxy) phenyl], 10,20- diphenyl porphyrin

$=$ Re- meso- 5,15- di [3,4- bis (carboxymethylenoxy) phenyl], 10,20- diphenyl porphyrin

$=$ meso- 5,10-cis- di [3,4- bis (carboxymethylenoxy) phenyl], 15,20- diphenyl porphyrin

$=$ meso $-5,10,15-\operatorname{tri}[3,4-$ bis (carboxymethylenoxy) phenyl $] 20$-phenyl porphyrin 
Table 1. The endocrine toxicity prediction

\begin{tabular}{clcccc}
\hline No. & Molecule & TOX_ER_Filter & TOX_ER $(\%)$ & TOX_AR_Filter & TOX_AR (\%) \\
\hline 1 & $\mathrm{M}_{3,4} \mathrm{BCPP}$ & Nontoxic $(82 \%)$ & Nontoxic & Toxic $(51 \%)$ & 0.0007 \\
2 & $\mathrm{D}_{3,4} \mathrm{BCPP}$ & Nontoxic & Nontoxic & Nontoxic & Nontoxic \\
3 & $\mathrm{Re}-\mathrm{D}_{3,4} \mathrm{BCPP}$ & Toxic & 0.0243 & Nontoxic & Nontoxic \\
4 & $\mathrm{cD}_{3,4} \mathrm{BCPP}$ & Nontoxic & Nontoxic & Nontoxic & Nontoxic \\
5 & $\mathrm{Tr}_{3,4} \mathrm{BCPP}$ & Nontoxic & Nontoxic & Nontoxic & Nontoxic \\
6 & $\mathrm{M}_{3,4} \mathrm{BCPTPP}$ & Toxic $(65 \%)$ & 0.0445 & Nontoxic & Nontoxic \\
7 & $\mathrm{D}_{3,4} \mathrm{BCPDPP}$ & Nontoxic & Nontoxic & Nontoxic & Nontoxic \\
8 & $\mathrm{Re}_{\mathrm{D}} \mathrm{D} 3,4 \mathrm{BCPDPP}$ & Toxic & 0.003 & Nontoxic & Nontoxic \\
9 & $\mathrm{cD}_{3,4} \mathrm{BCPDPP}$ & Nontoxic & Nontoxic & Nontoxic & Nontoxic \\
10 & $\mathrm{Tr}_{3,4} \mathrm{BCPPP}$ & Nontoxic & Nontoxic & Nontoxic & Nontoxic \\
\hline
\end{tabular}

Toxicity prediction was carried out using ADMET PredictorTM from SimulationsPlus.inc, including endocrine toxicity, maximum recommended therapeutic dose (MRTD), carcinogenicity and genotoxicity, cardiac toxicity, human liver adverse effects, acute rat toxicity, allergenic skin and respiratory sensitization, and reproductive toxicity.

\section{Results and Discussion}

The structure of all compounds were drawn using Gauss View 03 and optimized by Gaussian 03 Revission-B.04 to obtain the most stable conformation of the structure. Then, they were open by ADMET PredictorTM to perform the toxicity prediction.

\section{Endocrine toxicity}

Disruptions in endocrine system signaling can result from the interaction of drug compounds with the active site of the estrogen and/or androgen receptors. There, the compounds compete for binding with a sex hormone; the natural substrate for the receptor; blocking the transmission of normal hormonal signals and inducing toxicity.

The results (Table 1) showed that the $\mathrm{D}_{3,4} \mathrm{BCPP}$ and $\mathrm{D}_{3,4} \mathrm{BCPDPP}$ were precited to be nontoxic either to estrogen and androgen. It indicates that either $\mathrm{D}_{3,4} \mathrm{BCPP}$ and $\mathrm{D}_{3,4} \mathrm{BCPDPP}$ were unlikely to cause endocrine toxicity by binding to estrogen and/or androgen receptors. While their complexes to rhenium, Re$\mathrm{D}_{3,4} \mathrm{BCPP}$ and Re- $\mathrm{D}_{3,4} \mathrm{BCPDPP}$, were predicted to be toxic to the estrogen receptor by the relative binding affinity(RBA) of $0.0243 \%$ and $0.003 \%$ respectively. It indicates that these complexes were likely to bind detectably to to estrogen receptor and thus will cause toxicity. The RBA is a dimensionless number expressed as the percent ratio of $\mathrm{IC}_{50}$ for $17 \beta$ estradiol / $\mathrm{IC}_{50}$ for the compound. Higher value indicates greater binding affinity and likelihood for endocrine-related toxicity. The low RBA of these complexes indicates lower toxicity.
Maximum Recommended Therapeutic Dose

The unit of MRTD prediction is in $\mathrm{mg} / \mathrm{kg}$ of body weight/day. Prediction lower than $3.16 \mathrm{mg} / \mathrm{kg}$-bw/day indicates an active compound with significant potential for side effects. While the prediction higher than 3.16 $\mathrm{mg} / \mathrm{kg}$-bw/day indicates an inactive compound for which side effects are less likely [4].

The results (Table 2) showed that $\mathrm{D}_{3,4} \mathrm{BCPP}$ and $\mathrm{D}_{3,4} \mathrm{BCPDPP}$ have above $3.16 \mathrm{mg} / \mathrm{kg}$-bw/day which indicates these compounds are unlikely to cause potential side effects. While their complexes to rhenium, Re-D ${ }_{3,4}$ BCPP dan Re-D ${ }_{3,4}$ BCPDPP have below 3.16 $\mathrm{mg} / \mathrm{kg}-\mathrm{bw} /$ day which indicates these complexes are likely to cause potential side effects.

\section{Carcinogenicity and genotoxicity \\ ADMET Predictor's chronic carcinogenicity and mutagenicity models are built using data from the Carcinogenic Potency Database (CPDB). CPDB is a curated archive of compound names and tumorigenesis data that is available through the Environmental Protection Agency's DSSTox Program. It was compiled by the laboratory of Lois Swirsky Gold at the University of California Berkeley Lab. Two carcinogenicity models based on this data, TOX_BRM_RAT and TOX_BRM_Mouse, predict the $\mathrm{TD}_{50}$ value of a particular compound in units of $\mathrm{mg} / \mathrm{kg} / \mathrm{day}$. The $\mathrm{TD}_{50}$ is the dose of a substance administered orally to rats/mice over the course of their lifetimes that results in the appearance of tumors in 50 percent to their population.}


Table 2. MRTD prediction

\begin{tabular}{clc}
\hline No. & \multicolumn{1}{c}{ Molecule } & $\begin{array}{c}\text { TOX_MRTD } \\
(\mathrm{mg} / \mathrm{kg} / \text { day })\end{array}$ \\
\hline 1 & $\mathrm{M}_{3,4} \mathrm{BCPP}$ & Below_3.16 (59\%) \\
2 & $\mathrm{D}_{3,4} \mathrm{BCPP}$ & Above_3.16 \\
3 & $\mathrm{Re}-\mathrm{D}_{3,4} \mathrm{BCPP}$ & Below_3.16 \\
4 & $\mathrm{cD}_{3,4} \mathrm{BCPP}$ & Above_3.16 \\
5 & $\mathrm{Tr}_{3,4} \mathrm{BCPP}$ & Above_3.16 \\
6 & $\mathrm{M}_{3,4} \mathrm{BCPTPP}$ & Above_3.16 \\
7 & $\mathrm{D}_{3,4} \mathrm{BCPDPP}$ & Above_3.16 \\
8 & $\mathrm{Re}_{-} \mathrm{D}_{3,4} \mathrm{BCPDPP}$ & Below_3.16 \\
9 & $\mathrm{cD}_{3,4} \mathrm{BCPDPP}$ & Above_3.16 \\
10 & $\mathrm{Tr}_{3,4} \mathrm{BCPPP}$ & Above_3.16 \\
\hline
\end{tabular}

Table 3. Carcinogenicity and genotoxicity prediction

\begin{tabular}{clrc}
\hline No. & Molecule & $\begin{array}{r}\text { TOX_BRM_Rat } \\
(\mathrm{mg} / \mathrm{kg} / \text { day })\end{array}$ & $\begin{array}{r}\text { TOX_BRM_Mouse } \\
(\mathrm{mg} / \mathrm{kg} / \text { day })\end{array}$ \\
\hline 1 & $\mathrm{M}_{3,4} \mathrm{BCPP}$ & 2.05 & 379.18 \\
2 & $\mathrm{D}_{3,4} \mathrm{BCPP}$ & 29.2 & 1145.75 \\
3 & $\mathrm{Re}-\mathrm{D}_{3,4} \mathrm{BCPP}$ & 4.44 & 537.17 \\
4 & $\mathrm{cD}_{3,4} \mathrm{BCPP}$ & 65.8 & 1241.53 \\
5 & $\mathrm{Tr}_{3,4} \mathrm{BCPP}$ & 1048.91 & 2657.53 \\
6 & $\mathrm{M}_{3,4} \mathrm{BCPTPP}$ & 4.93 & 129.42 \\
7 & $\mathrm{D}_{3,4} \mathrm{BCPDPP}$ & 102.05 & 694.91 \\
8 & $\mathrm{Re}_{-} \mathrm{D}_{3,4} \mathrm{BCPDPP}$ & 14.65 & 283.36 \\
9 & $\mathrm{cD}_{3,4} \mathrm{BCPDPP}$ & 232.71 & 714.34 \\
10 & $\operatorname{Tr}_{3,4} \mathrm{BCPPP}$ & 1282.42 & 2236.68 \\
\hline
\end{tabular}

The results (Table 3) showed that $\mathrm{D}_{3,4} \mathrm{BCPP}$ and $\mathrm{D}_{3,4} \mathrm{BCPDPP}$ have a high TOX_BRM_Rat and TOX_BRM_Mouse value, and decrease when they are labeled by rhenium (Re-D ${ }_{3,4} \mathrm{BCPP}$ and $\mathrm{Re}-\mathrm{D}_{3,4} \mathrm{BCPDPP}$ ). It indicates that $\mathrm{D}_{3,4} \mathrm{BCPP}$ and $\mathrm{D}_{3,4} \mathrm{BCPDPP}$ have a low carcinogenicity and genotoxicity to both of rat and mouse. While the Re- $\mathrm{D}_{3,4} \mathrm{BCPP}$ and $\mathrm{Re}-\mathrm{D}_{3,4} \mathrm{BCPDPP}$ have a higher carcinogenicity and genotoxicity.

\section{Cardiac toxicity}

The human Ether-a-go-go Related Gene (hERG) encodes potassium channels, which are responsible for the normal repolarization of the cardiac action potential. Blockage or any other impairment of these channels in the heart cells can lead to fatal cardiac arrhythmias. Two neural network models are used to assess a compounds likelihood of blocking to the hERG channel, TOX_hERG_Filter and TOX_hERG. The first is a classification which detects whether the compound will have affinity for the hERG $\mathrm{K}^{*}$ channel. Compounds with an $\mathrm{IC}_{50}$ less than or equal to $10 \mu \mathrm{mol} / \mathrm{L}$ were labeled "Yes" which indicates that the compound is likely to block the hERG channel. While compounds with an $\mathrm{IC}_{50}$ greater than $10 \mu \mathrm{mol} / \mathrm{L}$ were labeled "No" which indicates that the compound is unlikely to block the hERG channel.

Table 4. Cardiac toxicity prediction

\begin{tabular}{clcc}
\hline No. & Molecule & TOX_hERG_Filter & $\begin{array}{c}\text { TOX_hERG } \\
(\mathrm{mol} / \mathrm{L})\end{array}$ \\
\hline 1 & $\mathrm{M}_{3,4} \mathrm{BCPP}$ & No & 5.34 \\
2 & $\mathrm{D}_{3,4} \mathrm{BCPP}$ & No & 5.47 \\
3 & $\mathrm{Re}-\mathrm{D}_{3,4} \mathrm{BCPP}$ & No & 5.08 \\
4 & $\mathrm{cD}_{3,4} \mathrm{BCPP}$ & No & 5.46 \\
5 & $\mathrm{Tr}_{3,4} \mathrm{BCPP}$ & No & 5.63 \\
6 & $\mathrm{M}_{3,4} \mathrm{BCPTPP}$ & No & 5.99 \\
7 & $\mathrm{D}_{3,4} \mathrm{BCPDPP}$ & No & 6.07 \\
8 & $\mathrm{Re}_{3,4} \mathrm{BCPDPP}$ & No & 5.61 \\
9 & $\mathrm{cD}_{3,4} \mathrm{BCPDPP}$ & No & 5.99 \\
10 & $\mathrm{Tr}_{3,4}$ BCPPP & No & 6.04 \\
\hline
\end{tabular}

The results (Table 4) showed that all compounds were predicted to have a high $\mathrm{IC}_{50}$ (greater than $10 \mu \mathrm{mol} / \mathrm{L}$ ). It indicates that all compounds are unlikely to block the hERG channels.

Furthermore, Ames mutagenicity test was carried out to predict the mutagenicity of the compounds to some Salmonella sp. strains. The Ames mutagenicity is a measurement of the mutagenic potential of chemical compounds developed by Bruce Ames and his group with the use of strains of the Salmonella typhimurium as an alternative to testing in rodents, which takes longer and costs more. The Ames Salmonella mutagenicity is a short-term bacterial reverse mutation assay that detects kinds of chemically-induced genetic damage that could lead to carcinogenesis in humans.

The results (Table 5) showed that all compounds give a negative prediction in Ames mutagenicity test to all Salmonella typhimurium mutans, except the Re$\mathrm{D}_{3,4} \mathrm{BCPP}$ that gives a positive prediction to TA102 strain which requiring microsomal activation mechanism.

\section{Human liver adverse effects}

The prediction of hepatotoxicity diagnostics uses five hepatic enzymes, including Alkaline Phosphatase (TOX_AlkPhos), Gamma-Glutamyl Transpeptidase, GGT (TOX_GGT), Lactate Dehydrogenase, LDH (TOX_LDH), Serum Glutamic Oxaloacetic Transaminase, SGOT (TOX_SGOT), dan Serum Glutamic Pyruvic Transaminase, SGPT (TOX_SGPT). An abnormal blood level elevation of any of the above enzymes was taken as an indicator of Adverse Drug Reaction (ADR) related activity. 
Table 5. Ames mutagenicity test

\begin{tabular}{clccccc}
\hline No. & Molecule & $\begin{array}{c}\text { TOX_MUT_ } \\
97+1537\end{array}$ & $\begin{array}{c}\text { TOX_MUT } \\
\text { m97+1537 }\end{array}$ & $\begin{array}{c}\text { TOX_MUT } \\
-98\end{array}$ & $\begin{array}{c}\text { TOX_MUT } \\
\_ \text {m98 }\end{array}$ & $\begin{array}{c}\text { TOX_MU } \\
\text { T_100 }\end{array}$ \\
\hline 1 & $\mathrm{M}_{3,4} \mathrm{BCPP}$ & Negative & Negative & Negative & Negative & Negative \\
2 & $\mathrm{D}_{3,4} \mathrm{BCPP}$ & Negative & Negative & Negative & Negative & Negative \\
3 & $\mathrm{Re}_{-} \mathrm{D}_{3,4} \mathrm{BCPP}$ & Negative & Negative & Negative & Negative & Negative \\
4 & $\mathrm{cD}_{3,4} \mathrm{BCPP}$ & Negative & Negative & Negative & Negative & Negative \\
5 & $\mathrm{Tr}_{3,4} \mathrm{BCPP}$ & Negative & Negative & Negative & Negative & Negative \\
6 & $\mathrm{M}_{3,4} \mathrm{BCPTPP}$ & Negative & Negative & Negative & Negative & Negative \\
7 & $\mathrm{D}_{3,4} \mathrm{BCPDPP}$ & Negative & Negative & Negative & Negative & Negative \\
8 & $\mathrm{Re}_{3, \mathrm{D}} \mathrm{BCPDPP}$ & Negative & Negative & Negative & Negative & Negative \\
9 & $\mathrm{cD}_{3,4} \mathrm{BCPDPP}$ & Negative & Negative & Negative & Negative & Negative \\
10 & $\mathrm{Tr}_{3,4} \mathrm{BCPPP}$ & Negative & Negative & Negative & Negative & Negative \\
\hline
\end{tabular}

Table 5. Ames mutagenicity test (continue)

\begin{tabular}{|c|c|c|c|c|c|c|}
\hline No & Molecule & $\begin{array}{c}\text { TOX_MUT_ } \\
\text { m100 }\end{array}$ & $\begin{array}{c}\text { TOX_MUT_ } \\
102+w p 2\end{array}$ & $\begin{array}{l}\text { TOX_MUT_ } \\
\text { m102+wp2 }\end{array}$ & $\begin{array}{c}\text { TOX_MUT } \\
1535\end{array}$ & $\begin{array}{l}\text { TOX_MU } \\
\text { T_m1535 }\end{array}$ \\
\hline 1 & $\mathrm{M}_{3,4} \mathrm{BCPP}$ & Negative & Negative & Negative & Negative & $\begin{array}{c}\text { Negative } \\
(99 \%)\end{array}$ \\
\hline 2 & $\mathrm{D}_{3,4} \mathrm{BCPP}$ & Negative & Negative & Negative & Negative & $\begin{array}{c}\text { Negative } \\
(99 \%)\end{array}$ \\
\hline 3 & Re- $\mathrm{D}_{3,4} \mathrm{BCPP}$ & Negative & Negative & Positive & Negative & $\begin{array}{c}\text { Negative } \\
(99 \%)\end{array}$ \\
\hline 4 & $\mathrm{cD}_{3,4} \mathrm{BCPP}$ & Negative & Negative & Negative & Negative & $\begin{array}{c}\text { Negative } \\
(99 \%)\end{array}$ \\
\hline 5 & $\mathrm{Tr}_{3,4} \mathrm{BCPP}$ & Negative & Negative & Negative & Negative & $\begin{array}{c}\text { Negative } \\
(99 \%)\end{array}$ \\
\hline 6 & $\mathrm{M}_{3,4}$ ВСРТРP & Negative & Negative & Negative & Negative & $\begin{array}{c}\text { Negative } \\
(99 \%)\end{array}$ \\
\hline 7 & $\mathrm{D}_{3,4} \mathrm{BCPDPP}$ & Negative & Negative & Negative & Negative & $\begin{array}{c}\text { Negative } \\
(99 \%)\end{array}$ \\
\hline 8 & Re-D ${ }_{3,4}$ BCPDPP & Negative & Negative & Negative & Negative & $\begin{array}{c}\text { Negative } \\
(99 \%)\end{array}$ \\
\hline 9 & $\mathrm{cD}_{3,4} \mathrm{BCPDPP}$ & Negative & Negative & Negative & Negative & $\begin{array}{l}\text { Negative } \\
(99 \%)\end{array}$ \\
\hline 10 & $\mathrm{Tr}_{3,4} \mathrm{BCPPP}$ & Negative & Negative & Negative & Negative & $\begin{array}{l}\text { Negative } \\
(99 \%)\end{array}$ \\
\hline
\end{tabular}


Table 6. Human liver adverse effects prediction

\begin{tabular}{lllllll}
\hline No. & Molecule & TOX_AlkPhos & TOX_GGT & TOX_LDH & TOX_SGOT & TOX_SGPT \\
\hline 1 & $\mathrm{M}_{3,4} \mathrm{BCPP}$ & Normal & Normal & Elevated & Normal & Normal \\
2 & $\mathrm{D}_{3,4} \mathrm{BCPP}$ & Normal & Normal & Elevated & Normal & Normal \\
3 & $\mathrm{Re}_{\mathrm{D}} \mathrm{D}_{3,4} \mathrm{BCPP}$ & Normal & Normal & Elevated & Normal & Elevated \\
4 & $\mathrm{cD}_{3,4} \mathrm{BCPP}$ & Normal & Elevated & Elevated & Normal & Elevated \\
5 & $\mathrm{Tr}_{3,4} \mathrm{BCPP}$ & Normal & Elevated & Elevated & Normal & Elevated \\
6 & $\mathrm{M}_{3,4} \mathrm{BCPTPP}$ & Normal & Elevated & Elevated & Normal & Elevated \\
7 & $\mathrm{D}_{3,4} \mathrm{BCPDPP}$ & Normal & Elevated & Elevated & Normal & Elevated \\
8 & $\mathrm{Re}_{3, \mathrm{D}} \mathrm{BCPDPP}$ & Normal & Elevated & Elevated & Normal & Elevated \\
9 & $\mathrm{cD}_{3,4} \mathrm{BCPDPP}$ & Normal & Elevated & Elevated & Normal & Elevated \\
10 & $\operatorname{Tr}_{3,4} \mathrm{BCPPP}$ & Normal & Elevated & Elevated & Normal & Elevated \\
\hline
\end{tabular}

The results showed (Table 6) that all compounds did not cause the blood level elevation of alkaline phosphatase and SGOT. Meanwhile, the $\mathrm{D}_{3,4} \mathrm{BCPDPP}$ and Re$\mathrm{D}_{3,4} \mathrm{BCPDPP}$ stimulate the blood level elevation of GGT, all compounds stimulate the blood level elevation of $\mathrm{LDH}$, and Re-D ${ }_{3,4} \mathrm{BCPP}, \mathrm{D}_{3,4} \mathrm{BCPDPP}$, and Re$\mathrm{D}_{3,4} \mathrm{BCPDPP}$ stimulate the blood level elevation of SGPT. It indicates that almost all of compounds are likely hepatotoxic.

\section{Acute Rat Toxicity}

The acute rat toxicity model is based on the amount of orally administered chemical in $\mathrm{mg} / \mathrm{kg}$ body weight that produced lethality in $50 \%\left(\mathrm{LD}_{50}\right)$ of the rats in each respective study regardless of the mode of action. Data for this study comes from two soures, the highly overlapping Registry of Toxic Effects of Chemical Substances (RTECS) data sets (version previously owned by the Center for Disease Control's National Institute for Occupational Safety and Health) and the ChemIDplus database (http://chem.sis.nlm.nih.gov/ chemidplus/).

The results (Table 7) showed that all compounds have a high $\mathrm{LD}_{50}$ which indicates that they have a low acute rat toxicity.

\section{Allergenic Skin and Respiratory Sensitization}

ADMET PredictorTM uses two models to predict the relative potency of skin and respiratory sensitizing chemicals. TOX_SKIN model states the skin sensitizing potency, while the TOKX_RESP states the respiratory sensitizing potency. The results (Table 8) showed that all compounds have an allergenic respiratory sensitization potency, but not to sensitize the skin allergy.
Table 7. Acute rat toxicity prediction

\begin{tabular}{clr}
\hline No. & Molecule & $\begin{array}{r}\text { TOX_RAT } \\
(\mathrm{mg} / \mathrm{kg})\end{array}$ \\
\hline 1 & $\mathrm{M}_{3,4} \mathrm{BCPP}$ & 1309.57 \\
2 & $\mathrm{D}_{3,4} \mathrm{BCPP}$ & 163.34 \\
3 & $\mathrm{Re}^{\mathrm{D}} \mathrm{D}_{3,4} \mathrm{BCPP}$ & 140.92 \\
4 & $\mathrm{cD}_{3,4} \mathrm{BCPP}$ & 148.94 \\
5 & $\mathrm{Tr}_{3,4} \mathrm{BCPP}$ & 87.88 \\
6 & $\mathrm{M}_{3,4} \mathrm{BCPTPP}$ & 130.98 \\
7 & $\mathrm{D}_{3,4} \mathrm{BCPDPP}$ & 71.22 \\
8 & $\operatorname{Re}^{-} \mathrm{D}_{3,4} \mathrm{BCPDPP}$ & 58.28 \\
9 & $\mathrm{cD}_{3,4} \mathrm{BCPDPP}$ & 85.93 \\
10 & $\mathrm{Tr}_{3,4} \mathrm{BCPPP}$ & 83.30 \\
\hline
\end{tabular}

Table 8. Allergenis skin and respiratory sensitization prediction

\begin{tabular}{clll}
\hline No. & Molecule & TOX_SKIN & TOX_RESP \\
\hline 1 & $\mathrm{M}_{3,4} \mathrm{BCPP}$ & Nonsensitizer & Sensitizer \\
2 & $\mathrm{D}_{3,4} \mathrm{BCPP}$ & Nonsensitizer & Sensitizer \\
3 & $\mathrm{Re}-\mathrm{D}_{3,4} \mathrm{BCPP}$ & Nonsensitizer & Sensitizer \\
4 & $\mathrm{CD}_{3,4} \mathrm{BCPP}$ & Nonsensitizer & Sensitizer \\
5 & $\mathrm{Tr}_{3,4} \mathrm{BCPP}$ & Nonsensitizer & Sensitizer \\
6 & $\mathrm{M}_{3,4} \mathrm{BCPTPP}$ & Nonsensitizer & Sensitizer \\
7 & $\mathrm{D}_{3,4} \mathrm{BCPDPP}$ & Nonsensitizer & Sensitizer \\
8 & $\mathrm{Re}_{\mathrm{D}} \mathrm{D}$ B, $\mathrm{BCPPP}$ & Nonsensitizer & Sensitizer \\
9 & $\mathrm{CD}_{3,4} \mathrm{BCPDPP}$ & Nonsensitizer & Sensitizer \\
10 & $\mathrm{Tr}_{3,4} \mathrm{BCPPP}$ & Nonsensitizer & Sensitizer \\
\hline
\end{tabular}

Reproductive Toxicity

Reproductive toxicity relates to anything that disturbs the reproductive process of organisms, including adverse 
effects to sexual organs, behavior, ease of conception, and developmental toxicity of offspring both before and after birth. The reproductive toxicity prediction uses TOX_REPR model based on the database that was constructed by researchers for the Department of Environmental and Occupational Health, University of Pittsburg.

Table 9. Reproductive toxicity prediction

\begin{tabular}{clc}
\hline No. & Molekul & TOX_REPR \\
\hline 1 & $\mathrm{M}_{3,4} \mathrm{BCPP}$ & Toxic \\
2 & $\mathrm{D}_{3,4} \mathrm{BCPP}$ & Toxic \\
3 & $\mathrm{Re}_{-} \mathrm{D}_{3,4} \mathrm{BCPP}$ & Toxic \\
4 & $\mathrm{cD}_{3,4} \mathrm{BCPP}$ & Toxic \\
5 & $\mathrm{Tr}_{3,4} \mathrm{BCPP}$ & Toxic \\
6 & $\mathrm{M}_{3,4} \mathrm{BCPTPP}$ & Toxic \\
7 & $\mathrm{D}_{3,4} \mathrm{BCPDPP}$ & Toxic \\
8 & $\mathrm{Re}_{-\mathrm{D}_{3,4} \mathrm{BCPDPP}}$ & Toxic \\
9 & $\mathrm{cD}_{3,4} \mathrm{BCPDPP}$ & Toxic \\
10 & $\mathrm{Tr}_{3,4} \mathrm{BCPPP}$ & Toxic \\
\hline
\end{tabular}

The results (Table 9) showed that all compounds are likely toxic to reproductive process of organisms.

\section{Conclusions}

Toxicity prediction using ADMET Predictor ${ }^{\mathrm{TM}}$ showed that $\mathrm{D}_{3,4} \mathrm{BCP}$ has an acute toxicity in rat; $\mathrm{D}_{3,4} \mathrm{BCPDPP}$ has an acute toxicity in rat and hepatotoxic; Re- $\mathrm{D}_{3,4} \mathrm{BCP}$ has an acute toxicity in rat, hepatotoxic, and likely carcinogenic in rat in which requiring microsomal activation mechanism; and $\mathrm{Re}-\mathrm{D}_{3,4} \mathrm{BCPDPP}$ has an acute toxicity in rat and hepatotoxic. However, in the radiopharmaceuticals, the important role for the effective therapy is not on the interaction of the drug molecule, but the radiation emitted by the radionuclides. Therefore, the dose of radiopharmaceutical used is very low, i.e. far below the therapeutic dose. Thus, the chemical toxicity is negligible.

\section{Acknowledgement}

FZ thanks the Managing Institute for Educational Fund (LPDP), Ministry of Finance, the Republic of Indonesia for the dissertation scholarship.

\section{References}

[1] S.J. Shetty, S. Murugesan, S.R. Chatterjee, S. Banerjee, T.S. Srivastava, Oliver P.D. Noronha, and A.M. Samuel, A New ${ }^{99 \mathrm{~m}}$ Tc Labeled Porphyrin for Specific Imaging of Sarcoma 120 Synthesis and Biological Study in a Swiss Mouse Model, Journal of Labelled Compounds and Radiopharmaceuticals, 38(5), 1996, 411-418.

[2] D.H. Tjahjono, T. Yamamoto, S. Ichimoto, N. Yoshioka, and H. Inoue, Synthesis and DNA-binding Properties of Bisdiazoliumylporphyrins, J. Chem. Soc., Perkin Trans., 2000, 3077-3082.

[3] ADMET Predictor ${ }^{\mathrm{TM}}$ User Manual, www.simulation-plus.com

[4] Z. Jia, H. Deng, and S. Luo, Rhenium-labelled meso-tetrakis [3,4-bis(carboxymethyleneoxy)phenyl]porphyrin for Targeted Radiotheraphy: Preliminary Biological Evaluation in Mice, Eur. J. Nucl. Med. Mol. Imaging, 35, 2008, 734-742. 